\title{
Test of indirect models of selection in the Trinidad guppy
}

\author{
FELIX BREDEN* \& KELLY HORNADAY† \\ Department of Biological Sciences, Simon Fraser University, Burnaby BC, Canada V5A 1 S6 and tDivision of Biological \\ Sciences, Tucker Hall, University of Missouri, Columbia MO 65211, USA
}

\begin{abstract}
Indirect models for the evolution of female preference assume that preference does not evolve as a result of direct selection but rather through genetic correlations with positively selected male traits. An essential assumption of Fisherian models and many recent good genes models is that assortative mating causes a genetic correlation to develop between alleles conferring high preference and alleles conferring high levels of the male attractive phenotype. In a direct test of indirect selection models, mass selection on attractive male coloration did not result in a correlated response in female preference in replicate treatments from a high predation population of the Trinidad guppy. The response was consistently low and a power analysis showed that genetic drift was not likely to explain the low response across all replicates. These results contrast with studies demonstrating such a correlation in another population of guppies and in three-spined sticklebacks.
\end{abstract}

Keywords: attractive male traits, female preference, genetic correlations, indirect selection, sexual selection, Trinidad guppy.

\section{Introduction}

Models of indirect selection can explain the evolution of female preference for exaggerated male secondary sexual characters, even when these exaggerated characters cause a decrease in survivorship of male offspring and when females gain little more than sperm from mating. The key to such models is that preference evolves as a consequence of genetic correlations with other positively selected traits and not from differences in reproduction and survivorship between preferential and nonpreferential females (Heisler et al., 1987). One such model, Fisher's runaway process, assumes that assortative mating causes a genetic correlation to develop between female preference and the exaggerated male character. This can then lead to strong, selfreinforcing selection on preference and the attractive male character. Consequently, the Fisher effect has been proposed as an important force driving the evolution of female preference and ultimately speciation (Lande, 1981, 1982). Alternatively, 'good genes' types of models, where the attractive male character is genetically correlated with another character under direct positive natural selection, have also been proposed to explain the evolution of female preference (Maynard Smith, 1991). In these models female prefer-

\footnotetext{
*Correspondence.
}

ence evolves because of a genetic correlation with the male character under direct selection. However, many recent versions of these models also lead to a genetic correlation between alleles increasing preference for the attractive male character and alleles increasing the expression of the attractive male trait (Kirkpatrick, 1986; Bakker, 1993).

Selection experiments provide a powerful tool to examine these genetic correlations. If there were a genetic correlation between preference and the preferred character, then selection for high or low levels of the attractive male character should result in increased or decreased levels of female preference. In general, by artificially selecting on the attractive male character and then measuring what characters increase or decrease in selected populations, it should be possible to explore the indirect payoffs that accrue to females as a result of choice.

In the Trinidad guppy, there is a well-documented tradeoff between sexual and natural selection, with strong female preference for conspicuous males balanced by natural selection against such males (Endler, 1980). This balance between sexual and natural selection is reflected in a correlation between female preference and attractive male characters across populations (Breden \& Stoner, 1987; Houde, 1988; Stoner \& Breden, 1988; Houde \& Endler, 1990; Luyten \& Liley, 1991). To test for a within-population 
genetic correlation between attractive male coloration and female preference, divergent selection on total coloration was performed on replicates starting with guppies collected from a high predation population. Females from these replicates were then tested for strength of preference for a colourful or noncolourful male. This experiment also allowed us to examine whether other components of male conspicuousness, namely size and courtship activity, were correlated with attractive coloration.

\section{Materials and methods}

Guppies were collected from an area experiencing a high degree of predation on the lower Aripo River in Trinidad in January 1989. Each of four replicate populations was begun with 25 inseminated adult females collected from the field. Replicates were raised in plastic wading pools that were $2 \mathrm{~m}$ in diameter and held approximately $600 \mathrm{~L}$. The light regime was $14 \mathrm{~h}$ light to $10 \mathrm{~h}$ dark and replicates were fed Tetramin daily supplemented by live brine shrimp nauplii twice weekly.

For each generation, replicates were allowed to grow until a size of approximately 200 adults and 500-1000 juveniles. These were then removed from the pools and censused. Forty adult males from each replicate were photographed and the standard length (SL) and proportion of body covered by pigmented spots were recorded using a digitizing tablet interfaced with a microcomputer. In two high-selected lines the next generation was begun with five males with the highest proportion of the body covered with pigmentation, whereas in the two low-selected lines the five males with the lowest proportion of the body covered with pigmentation were chosen to begin the next generation. Twenty virgin females per replicate were chosen at random to begin the next generation. Each male was housed for $72 \mathrm{~h}$ with four females randomly chosen from his replicate. This maximized the probability that all males would receive some matings, thus reducing the effect of uncontrolled sexual selection occurring within each generation of mass selection. The five males and 20 females per replicate were then placed back into the wading pools to begin the next generation.

Selection on coloration was carried out for five generations (Fig. 1). After the fourth generation, the 40 males photographed from each replicate were also tested for level of courtship activity. The test aquarium was $50 \mathrm{~cm}$ long, divided into two sections by reflecting glass. Males were placed in one compartment such that they could see three adult females in the second compartment, providing a stimulus for male courtship

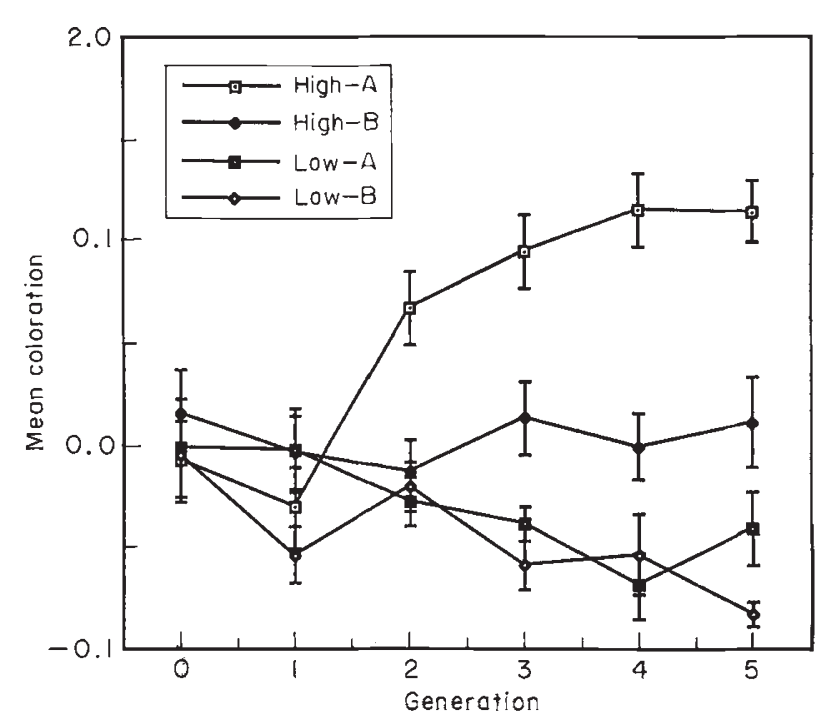

Fig. 1 Mean coloration in two high- and two low-selected lines for initial population (generation 0 ) and five generations of selection, plotted as deviations from each generation's grand mean coloration. Error bars indicate two standard errors above and below replicate mean.

activity. The females were not able to see the male, and thus would not be expected to adjust their behaviour depending on intrinsic preferences for male coloration. The same test females were used for all male assays. Males were coded such that the observer did not know from which replicate they were derived. Following a $10 \mathrm{~min}$ equilibration period, the number of sigmoid displays (Baerands et al., 1955) in the next $10 \mathrm{~min}$ period was recorded and reported as male courtship activity. All tests were conducted between 09.00 and 11.00 hours over the span of 2 weeks. The effect of replicate on activity level was tested with a simple oneway analysis of variance.

After the fifth generation, 39 females from each replicate were tested for choice of a colourful or a less colourful male in partitioned aquaria tests. Test males came from isofemale lineages that had been initiated with inseminated females from the same population used for the mass selection experiment. One colourful and one noncolourful isofemale lineage were used to produce three pairs of test males matched for size and overall behavioural activity. The average coloration of the colourful test males was 0.375 and of the less colourful test males was 0.222 . There was no effect of male pair on female choice scores $(P>0.9)$.

In each choice test, a female was placed in the centre of an aquarium divided into three partitions. The centre partition was $25 \mathrm{~cm}$ in length and the two end partitions were $12.5 \mathrm{~cm}$ each. Black removable dividers visually separated the female from the male 
stimuli during an initial $10 \mathrm{~min}$ equilibration period. The observer sat behind a black cloth screen observing the test tank through an eye slit. Once the plastic dividers were removed, a microcomputer was used to record female behaviour for $10 \mathrm{~min}$. Females were coded such that the observer did not know from which replicate they were derived. All females tested were greater than $15 \mathrm{~mm} \mathrm{SL}$. The test environment included five females in a separate tank toward the rear, visible from the female's compartment. Thus, motivation to school with conspecifics would most likely be observed as association with females at the rear of the tank as opposed to movement toward courting males.

Female choice behaviour was scored as the time spent oriented toward the colourful or the less colourful male, defined as being within $5 \mathrm{~cm}$ of the male's partition and facing the male. A choice score was calculated as $(\mathrm{C}-\mathrm{LC}) /(\mathrm{C}+\mathrm{LC})$, where $\mathrm{C}$ is the number of seconds spent oriented toward the colourful male and LC is the number of seconds spent oriented toward the less colourful male. Results for the effect of replicate on choice score were analysed by a general linear model analysis of variance, adjusting for several uncontrolled covariates: size of female, time of day and date of test (SAS 1982). Males removed from the replicates were photographed at the same time. Therefore the effect of replicate on male size was tested with a simple one-way analysis of variance.

\section{Results}

Figure 1 presents the results of five generations of selection and shows that there was a clear effect of replicate on male coloration for generations 3-5 $(P<0.001$, one-way analysis of variance). By the fifth generation of selection, the High-A replicate had reached an asymptote whereas the other high-selected line was not responding to selection. No further increase in coloration resulting from positive selection was to be expected and selection was discontinued.
After the fourth generation of selection, male courtship activity was measured on 40 males from each replicate. Table 1 shows the mean coloration and mean activity level for these males. There was a significant effect of replicate on male activity level $(P<0.01$, oneway analysis of variance), ranging from 1.0 to 4.7 displays per 10 min period. However, these differences did not correlate with selection regime. The replicate responding most strongly to selection for coloration, High-A, had the lowest courtship rate $(1.00)$ whereas the other high-selected line had a high courtship rate (4.30). Selection for low level of coloration produced lines with both high and low courtship activity.

Table 2 shows the mean coloration and size of males, and female preferences for a colourful and a noncolourful male, after five generations of selection. There was a significant effect of replicate on male size $(P<0.001$, one-way analysis of variance), ranging from 14.74 to $15.84 \mathrm{~mm} \mathrm{SL}$ per replicate. However, this effect again did not correlate with selection regime. For example, selection for low coloration produced lines with both high and low mean male size (15.73 and $14.74 \mathrm{~mm} \mathrm{SL}$ ).

Females from these replicates were then tested for preference between a colourful and a relatively less colourful male. Table 2 shows that there was an overall bias toward the more colourful male in all replicates, with mean choice scores ranging from 0.224 to 0.308 . However, there was no significant effect of replicate on female choice score $(P>0.7$, Table 3$)$ and the trends did not go in the predicted direction. High-A had the highest coloration and highest mean choice score whereas Low-B had the lowest coloration score but the second highest choice score.

Given that there was no effect of replicate on choice score, even though the replicates did differentiate in colour, it is important to ask whether genetic drift could explain this lack of response. For this purpose, each of the four replicates can be treated as an independent evolutionary event estimating the strength of the correlated response. The variance among replicates measures the deviation from the parametric value of

Table 1 Mean male coloration and courtship activity after four generations of selection for high and low male coloration

\begin{tabular}{lcccccc}
\hline Replicate & $\begin{array}{c}\text { Mean male } \\
\text { coloration }\end{array}$ & $N$ & SE & $\begin{array}{c}\text { Mean male } \\
\text { courtship }\end{array}$ & $N$ & SE \\
\hline High-A & 0.495 & 32 & 0.009 & 1.000 & 40 & 0.312 \\
High-B & 0.379 & 37 & 0.008 & 4.300 & 40 & 0.960 \\
Low-A & 0.311 & 36 & 0.008 & 2.250 & 40 & 0.770 \\
Low-B & 0.326 & 35 & 0.010 & 4.675 & 40 & 0.894 \\
Grand mean & 0.380 & & & 3.056 & & \\
\hline
\end{tabular}


Table 2 Mean male coloration and size, and mean choice scores of females, after five generations of selection for high and low male coloration

\begin{tabular}{lccccccccr}
\hline Replicate & $\begin{array}{c}\text { Mean male } \\
\text { coloration }\end{array}$ & $N$ & SE & $\begin{array}{c}\text { Mean male } \\
\text { size }\end{array}$ & $N$ & SE & $\begin{array}{c}\text { Mean female } \\
\text { choice score }\end{array}$ & $N$ & SE \\
\hline High-A & 0.452 & 39 & 0.015 & 15.55 & 39 & 0.192 & 0.308 & 39 & 0.079 \\
High-B & 0.349 & 39 & 0.011 & 15.84 & 39 & 0.171 & 0.224 & 41 & 0.083 \\
Low-A & 0.297 & 39 & 0.009 & 14.74 & 39 & 0.153 & 0.232 & 39 & 0.088 \\
Low-B & 0.255 & 39 & 0.006 & 15.73 & 39 & 0.148 & 0.280 & 37 & 0.106 \\
Grand mean & 0.338 & & & 15.46 & & & 0.260 & & \\
\hline
\end{tabular}

Table 3 General linear model analysis of variance for the effect of replicate on arcsin square root transform of the female choice score

\begin{tabular}{lrccc}
\hline Source & d.f. & Sum of squares & $F$ & $P$ \\
\hline Standard length & 1 & 0.0005 & 0.08 & 0.779 \\
Date & 1 & 0.239 & 3.96 & 0.049 \\
Time of day & 1 & 0.000 & 0.00 & 0.983 \\
Replicate & 3 & 0.079 & 0.44 & 0.727 \\
Error & 120 & & & \\
\hline
\end{tabular}

Standard length, date and time were analysed as uncontrolled covariates.

the correlated response that occurs from chance sampling. Thus, each replicate measures the strength of indirect selection and the variance among replicates can be used as an estimate of the force of drift in our selection regime (Henderson, 1989).

According to quantitative genetic theory, the observed correlated response is determined by:

$$
C R_{\mathrm{P}}=i h_{\mathrm{T}} h_{\mathrm{P}} r_{\mathrm{A}} s_{\mathrm{P}} \text {, }
$$

where $C R_{\mathrm{P}}$ is the correlated change in character $\mathrm{P}$, female choice, as a result of selection on character $T$, male coloration, $i$ is the intensity of selection on male coloration, $h_{\mathrm{T}}$ and $h_{\mathrm{P}}$ are the square roots of the heritabilities of the two characters, $r_{\mathrm{A}}$ is the genetic correlation between choice and coloration and $s_{\mathrm{P}}$ is the phenotypic standard deviation for female choice (Falconer, 1981). In our experiment, the response to selection on male coloration can be used to calculate the realized heritability of male coloration in each replicate, and the intensity of selection and phenotypic standard deviation of the female character per replicate are known. Thus eqn 1 can be used to estimate the product of the square root of the heritability of female choice multiplied by the genetic correlation between female choice and attractive male character. In this situation, the product of these parameters determines the correlated response and thus the potential for indirect selection.

The four estimates of this product are consistently small: $0.0193,-0.0468,0.022$ and -0.0131 (Table 4). The variance of these four estimates can be used to estimate the sampling variance of this product in a power analysis. We performed a power analysis assuming an alpha level of 0.05 and a one-tailed null hypothesis that this product was 0.0 ; i.e. the ability to detect a deviation from 0.0 was equated with a power greater than 0.95 (Sokal \& Rohlf, 1981). This power analysis showed that the experimental design would have been expected to detect a product of these two parameters greater than 0.06 (Table 4).

If we also have an estimate of the heritability of female choice, then eqn 1 can be used to estimate $r_{\mathrm{A}}$, the genetic correlation. Previous experiments in which females were measured twice for a choice of a colourful or noncolourful male showed that choice scores often have low repeatabilities ( $K$. Hornaday \& F. Breden, unpublished data), which would imply that this character has a low heritability (Falconer, 1981). Using two low values for the heritability of female choice, 0.25 and 0.1 , the genetic correlation between choice and the attractive male character is estimated to range from -0.148 to 0.067 (Table 4). A power analysis on the estimates from the four replicates showed that the design would be expected to detect a genetic correlation greater than 0.2 and 0.11 , under the assumption of a heritability of female choice of 0.25 and 0.1 , respectively.

\section{Discussion}

Three generations of strong selection was sufficient to differentiate the replicates for male coloration, measured as the proportion of body covered by pigmented spots. Figure 1 shows that one replicate responded strongly to positive selection and two replicates responded to negative selection. This significant 
Table 4 Correlated response in female choice (deviation of the replicate mean from the generation's grand mean after five generations of selection), intensities of selection (cumulative selection differential summed over five generations), realized heritabilities for male coloration, phenotypic standard deviation of female choice scores and estimates of genetic correlation given two assumed levels of heritability for female choice $\left(h_{\mathrm{P}}^{2}\right)$

\begin{tabular}{lccccrr}
\hline Replicate & $\begin{array}{c}\text { Correlated response } \\
\text { in female choice }\end{array}$ & $\begin{array}{c}\text { Intensity of } \\
\text { selection }\end{array}$ & $\begin{array}{c}\text { Realized } \\
\text { heritability }\end{array}$ & $\begin{array}{c}\text { Phenotypic } \\
\text { deviation of } \\
\text { choice score }\end{array}$ & \multicolumn{2}{c}{\begin{tabular}{r} 
Estimate of genetic correlation \\
\cline { 6 - 7 }
\end{tabular}} \\
\hline High-A & 0.048 & 8.52 & 0.335 & 0.499 & 0.039 & 0.061 \\
High-B & -0.037 & 6.84 & 0.047 & 0.531 & -0.094 & -0.148 \\
Low-A & -0.028 & -6.159 & 0.145 & 0.548 & 0.044 & 0.070 \\
Low-B & 0.019 & -4.94 & 0.211 & 0.642 & -0.027 & -0.042 \\
\hline
\end{tabular}

response to selection on coloration in three of four replicates supports the results of Houde (1991), which demonstrated strong heritability for orange coloration in male guppies from the Paria River in Trinidad. Thus, selection in natural populations presumably has not depleted genetic variance for these attractive male characters. Such additive variance is necessary for the various models of sexual selection to proceed.

Even though the replicates were strongly differentiated for coloration, male courtship frequency and male size did not change in a predictable manner (Tables 1 and 2). For example, lines selected for both high and low male coloration produced low courtship activity. This would suggest that there was not a strong genetic covariance between male coloration and these other components of male conspicuousness. The disparity in the direction of change among replicates is probably the result of genetic drift acting on courtship frequency or size directly, with some replicates receiving males with high activity levels or large size and others with low activity or small size, or genetic drift acting on the genetic covariances between coloration and these characters. If there were genetic drift in the covariances, then as we selected on coloration, there would be an unpredictable correlated response in the activity level or size of males in each replicate. Because of the possibility of drift, our conclusion that the components of male conspicuousnes are not strongly correlated should be regarded as tentative at this time.

On the other hand, the correlated response for female choice score was consistently low for all replicates. The power analysis performed on these choice scores showed that, if the potential for indirect selection existed, then some response would probably have been observed. Thus genetic drift is not a probable explanation for the lack of response in all four replicates.

If the genes for preference and preferred character are not physically linked, then recombination would reduce the genetic correlation by 50 per cent each generation. This effect would be expected to reduce the effectiveness of indirect selection and our ability to detect a correlation. We exerted a strong selection differential (five of 40 males) to produce a change in coloration in as few generations as possible, in order to minimize this effect. However, this may partly explain why no correlated response was observed in this experiment.

These results contrast with a selection experiment performed by Houde (1994) on a population from the northern-flowing Paria River. In her study, two of four replicates showed a response in female preference for orange males in response to divergent selection on orange males, indicating some genetic correlation between these characters. The Paria River populations have a very different predation regime with reduced predation compared with the high predation populations of the southern-flowing Aripo River. The correlation may be low in the high predation Aripo River population simply because assortative mating is reduced (Breden \& Stoner, 1987; Stoner \& Breden, 1988; Luyten \& Liley, 1991) and hence the potential for assortative mating to produce a genetic correlation is reduced. Although assortative mating is reduced in these high predation populations, there is still a significant bias toward colourful males, as shown in Table 2. Thus the conditions for assortative mating to produce a correlation between preference and preferred trait exist, but our results suggest that the correlation has not developed. Our results also contrast with those of Bakker on the three-spined stickleback, who observed a clear correlation between preference for red in females and level of redness in males (Bakker, 1993).

At least two studies on insects show some evidence for correlated responses. Wilkinson \& Reillo (1994) selected on male relative eye span in stalk-eyed flies and observed a clear correlated response in female preference for this character. De Winter (1992) selected on interpulse interval in female calls of a plant- 
hopper and observed that males preferred females from their own selection regime. However, the results on assortative mating in this study were contradictory, depending on the type of choice test performed on the males.

One possible criticism of our experiment is that the two-way choice tests do not measure female mating preference directly. However, females in the partitioned aquaria respond to courting males with the same type of orientation and other behaviours indicating female sexual receptivity as are observed in open field tests, and data from studies directly measuring mating success have corroborated results from tests measuring only female responses independent of copulation (Bischoff et al., 1985; Houde, 1987).

There are several components to male conspicuousness, including size, proportion of body covered by pigmentation and courtship frequency. The component chosen for direct selection was the most appropriate for this population for several reasons. Laboratory experiments using populations from the same stream in Trinidad showed that in the absence of predators overall diversity of coloration, number of pigmented spots and total coloration adjusted for body size increased because of female choice (Endler, 1980). This effect was most significant for blue and iridescent spots and least important for black or orange spots. Laboratory populations maintained in the presence of a dangerous cichlid predator showed a corresponding decrease in these characters, and field introductions corroborated these laboratory results (Endler, 1980). Thus, we decided to use the easily assessed character of proportion of body covered by pigmented spots as the target of selection.

In summary, artificial direct selection resulting in strong differentiation for attractive male coloration was shown to be very inefficient in causing the evolution of female preference in this population. Although several studies have shown some correlated response to indirect selection, our results combined with recent studies supporting direct selection on female preference independent of sexual selection (Kirkpatrick \& Ryan, 1991) suggest that more studies are needed before indirect selection is taken as a general explanation for the evolution of female preference.

\section{Acknowledgements}

We thank J. Bull, J. Endler, C. Gerhardt, M. Morris, M. Ryan, H. B. Shaffer and M. Wade for comments on the manuscript and M. Kirkpatrick and A. Pomiankowski for discussion on indirect models of sexual selection. The Trinidad Ministry of Agriculture, Lands and Fisheries granted permission to export fish. This work was supported by a grant from the NSF to F.B.

\section{References}

BAKKER, T. C. M. 1993. Positive genetic correlation between female preference and preferred male ornament in sticklebacks. Nature, 363, 255-257.

BAERENDS, G. P., BROUWER, L. AND WATERBOLK, H. T. 1955. Ethological studies on Lebistes reticulatus (Peters). Behaviour, 8, 249-335.

BISCHOFF, R. J., GOULD, J. L. AND RUBENSTEIN, D. I. 1985. Tail size and female choice in the guppy (Poecilia reticulata). Behav. Ecol. Sociobiol., 17, 253-255.

BREDEN, F. AND STONER, G. 1987. Male predation risk determines female preference in the Trinidad guppy. Nature, 329, 831-833.

DE WINTER, A. J. 1992. The genetic basis and evolution of acoustic mate recognition signals in a Ribautodelphax planthopper (Homoptera, Delphacidae). 1. The female call. J. Evol. Biol., 5, 249-265.

ENDLER, J. A. 1980. Natural selection on color patterns in Poecilia reticulata. Evolution, 34, 76-91.

FALCONER, D. S. 1981. Introduction to Quantitative Genetics, 2nd edn. The Ronald Press, New York.

HEISLER, L., ANDERSSON, M. B., ARNOLD, S. J., BOAKE, C. R., BORGIA, G., HAUSFATER, G., KIRKPATRICK, M., LANDE, R., MAYNARD SMITH, J., O'DONALD, P., THORNHILL, A. R. AND WEISSING, F. J. 1987. The evolution of mating preferences and sexually selected traits. Group Report. In: Bradbury, J. W. and Andersson, M. B. (eds) Sexual Selection: Testing the Alternatives, pp. 96-118. John Wiley, New York.

HENDERSON, N. D. 1989. Interpreting studies that compare high- and low-selected lines on new characters. Behav. Genet., 19, 473-502.

HOUDE, A. E. 1987. Mate choice based upon naturally occurring color-pattern variation in a guppy population. Evolution, 41, 1-10.

HOUDE, A. E. 1988. Genetic difference in female choice between two guppy populations. Anim. Behav., 36, 510-516.

HOUDE, A. E. 1991. Sex-linked heritability of a sexually selected character in a natural population of Poecilia reticulata (Pisces: Poeciliidae) (guppies). Heredity, 69, 229-235.

HOUDE, A. E. 1994. Evolution of female mating preference as an indirect response to selection on males. Proc. R. Soc. Lond. $B$ (in press).

HOUDE, A. E. AND ENDLER, J. A. 1990. Correlated evolution of female mating preferences and male color patterns in the guppy, Poecilia reticulata. Science, 248, 1405-1408.

KIRKPATRICK, M. 1986. Sexual selection and cycling parasites: a simulation study of Hamilton's hypothesis. J. Theor. Biol., 119, 263-271.

KIRKPATRICK, M. AND RYAN, M. J. 1991. The evolution of mating preferences and the paradox of the lek. Nature, 350, 33-38.

LANDE, R. 1981. Models of speciation by sexual selection on polygenic traits. Proc. Natl. Acad. Sci. U.S.A., 78, 3721-3725.

LANDE, R. 1982. Rapid origin of sexual isolation and character divergence in a cline. Evolution, 36, 213-223. 
LUYTEN, P. H. AND LILEY, N. R. 1991. Sexual selection and competitive mating success of males (sic)guppies (Poecilia reticulata) from four Trinidad populations. Behav. Ecol. Sociobiol., 28, 329-336.

MAYNARD SMITH, J. 1991. Theories of sexual selection. Trends Ecol. Evol., 6, 146-151.

SAS USER'S GUIDE. 1982. Statistics. SAS Institute, Cary, NC. SOKAL, R. R. AND ROHLF, F. J. 1981. Biometry. W. H. Freeman, San Francisco, p. 166.
STONER, G. AND BREDEN, F. 1988. Phenotypic differentiation in female preference related to geographic variation in male predation risk in the Trinidad guppy (Poecilia reticulata). Behav. Ecol. Sociobiol., 22, 285-291.

WILKINSON, G. AND REILLO, P. R. 1994. Female choice response to artificial selection on an exaggerated male trait in a stalkeyed fly. Proc. R. Soc. Lond. B, 255, 1-6. 